\title{
A Multiplex PCR Assay for Detection of Pseudomonas syringae pv. actinidiae and Differentiation of Populations with Different Geographic Origin
}

G. M. Balestra, Department of Science and Technologies for Agriculture, Forestry, Nature and Energy, and M. C. Taratufolo, Department of Science and Technologies for Agriculture, Forestry, Nature and Energy, University of Tuscia, Viterbo, Italy; B. A. Vinatzer, Department of Plant Pathology, Physiology, and Weed Science, Virginia Tech, Blacksburg; and A. Mazzaglia, Department of Science and Technologies for Agriculture, Forestry, Nature and Energy, University of Tuscia, Viterbo, Italy

\begin{abstract}
Balestra, G. M., Taratufolo, M. C., Vinatzer, B. A., and Mazzaglia, A. 2013. A multiplex PCR assay for detection of Pseudomonas syringae pv. actinidiae and differentiation of populations with different geographic origin. Plant Dis. 97:472-478.

Pseudomonas syringae pv. actinidiae is responsible for severe outbreaks of bacterial canker of kiwifruit currently occurring around the world. Although molecular detection methods have been reported, none provide complete selectivity for this pathovar or discriminate among pathogen haplotypes. Therefore, a new multiplex polymerase chain reaction (PCR) assay was developed and validated. The assay was tested on $32 P$. syringae pv. actinidiae isolates and 15 non- $P$. syringae pv. actinidiae strains and correctly assigned $P$. syringae pv. actinidiae strains to three different haplotypes: a Japanese/Korean group, a European group, and a Chinese group. Two $P$. syringae pv. actinidiae

isolates from New Zealand were found to belong to the Chinese group whereas two other isolates from New Zealand, which were isolated from kiwifruit plants but which do not cause bacterial canker, tested negative. The described PCR assays has a limit of detection of approximately 5 to $50 \mathrm{pg}$ of purified DNA or of $5 \times 10^{2}$ bacteria/PCR and were shown to work with both artificially and naturally infected plant tissues. Thus, the described method represents a suitable tool for detection of $P$. syringae pv. actinidiae and haplotype attribution, in particular, when testing a high number of samples during surveillance and prevention activities.
\end{abstract}

Pseudomonas syringae is a bacterial species that includes dozens of pathogenic variants that may be highly aggressive on many plant species. These variants are assigned to intraspecific taxa named "pathovars" according to their host range and the symptoms they cause (39). Pathovar actinidiae is the taxon of $P$. syringae that causes bacterial canker of kiwifruit (34). This disease was first observed on kiwi in 1984-85 in Hunan Province, China (13), and the pathogen was first isolated and exhaustively described in Japan in 1989 on the green-fleshed species Actinidia deliciosa L. (32). The disease was later found in Korea $(18,19)$ and Italy $(29)$. However, $P$. syringae pv. actinidiae did not cause severe damages until 2008, when a dramatic outbreak due to a new, more aggressive haplotype occurred in Italy (1-3,23). This outbreak is still continuing today. In 2010, the same haplotype was also reported in Portugal (4), France (36), and New Zealand (12); and, in 2011, it reached Australia (8), Spain (5), Switzerland (11), and Chile (10). The presence of the pathogen was also reported in Turkey (7). Within a few years, this new canker disease has grown to an international pandemic that is now threatening the sustainability of the kiwi industry in all major kiwi-producing countries.

The worldwide $P$. syringae pv. actinidiae population consists of different subpopulations $(9,14,16,22-24,30,37)$ that seem to be characterized by different levels of aggressiveness toward kiwifruit. The strains isolated in Europe since 2008 and some of the strains isolated in New Zealand in 2010-11 are considered the most virulent by far, also defined as haplotype PSA-1 or PSA-V (9), based on their aggressiveness and rapidity of their spread. In New Zealand, another population (labeled as haplotype PSA-2 or PSA-LV) was described. Strains belonging to this population only cause leaf spots but no cankers (9).

Corresponding author: A. Mazzaglia, E-mail: angmazza@unitus.it

Accepted for publication 26 September 2012.

http://dx.doi.org/10.1094/PDIS-06-12-0590-RE

(c) 2013 The American Phytopathological Society
In regard to Asia, the data available today suggest that $P$. syringae pv. actinidiae strains from Japan and Korea belong to one population within which two different haplotypes can be distinguished based on presence or absence of gene clusters coding for the toxins coronatine and phaseolotoxin $(16,21)$. The only Chinese strains analyzed so far were closely related both to the European and New Zealand strains: only six mutations (single nucleotide polymorphisms [SNPs]) in 3.5 million bp of genome sequence distinguish Chinese $P$. syringae pv. actinidiae strains from the European $P$. syringae pv. actinidiae strains and only one difference in gene content within a genomic island similar to PPHGI-1 could be detected (24). Interestingly, when two New Zealand PSA-V strains were compared with the European and the Chinese $P$. syringae pv. actinidiae strains, they resembled the European strains in regard to the six SNPs but were identical to the Chinese strains in regard to gene content within the PPHGI-1 genomic island (24). Using parsimony, the most likely explanation of this finding is that importation of $P$. syringae pv. actinidiae from China into Europe and into New Zealand were two independent events because this scenario can be explained with one lateral gene transfer event, whereas importation of $P$. syringae pv. actinidiae from China into Europe and from there into New Zealand would imply two lateral gene transfer events (24).

Due to the co-existence on kiwifruit plants of $P$. syringae pv. actinidiae with other pathogens, such as $P$. syringae pv. syringae and $P$. viridiflava, as well as fungi, viruses, and insects, neither classical approaches such as isolation and cultivation on appropriate media nor identification by standard laboratory tests and implementation of Koch's postulates are specific enough to determine unequivocally the identity of the pathogen. Furthermore, these procedures are time consuming and, therefore, unsuitable for a rapid response for disease management, quarantine analysis, and determining whether plants are $P$. syringae pv. actinidiae-free before planting them in new orchards.

In recent decades, molecular analyses using polymerase chain reaction (PCR) has proven to be a powerful tool for detecting specific bacteria, often without the need for culturing. Also, for $P$. syringae pv. actinidiae, various PCR assays have been developed $(15,20,28,31)$ but, unfortunately, most of these assays lack in speci- 
ficity (26) and none of them can simultaneously distinguish between different populations of $P$. syringae pv. actinidiae. Here, we describe a new, highly specific multiplex PCR assay based on our recent comparative evolutionary genomics study of $P$. syringae pv. actinidiae (24). This assay distinguishes $P$. syringae pv. actinidiae from all other pseudomonads and can putatively assign $P$. syringae pv. actinidiae strains to populations of different geographic origin.

\section{Materials and Methods}

Bacterial strains and culturing. A set of 32 strains (Table 1) was selected from a collection of about 150 P. syringae pv. actinidiae strains isolated between 1984 and 2011 from almost all areas of kiwifruit cultivation infested by the disease. The selected strains, which are representative of all $P$. syringae pv. actinidiae populations described to date, were used for assay development and validation. All strains available to us from Japan (six strains), Korea (three strains), China (three strains), and New Zealand (four strains) were included. On the other hand, due to the availability of about 120 European strains, a random selection of 16 was made (but acting so that every interested country was represented by at least one strain); this included 7 strains from all Italian regions where the disease has been reported to date, 2 from Spain, 3 from Portugal, 3 from France, and 1 from Switzerland. Additionally, strains belonging to 10 pathovars related to $P$. syringae pv. actinidiae were used as negative controls: $P$. syringae pv. theae (two strains); $P$. syringae pv. avellanae, today reclassified as $P$. avellanae (17) (three strains); $P$. syringae pv. morsprunorum; $P$. syringae pv. tomato; $P$. syringae pv. maculicola; $P$. syringae pv. papulans; $P$. syringae pv. syringae (two strains); $P$. syringae pv. lachrymans; $P$. syringae pv. aptata; and $P$. syringae pv. pisi. An individual of $P$. viridiflava isolated from A. chinensis was also included (Table 1). All bacterial strains are stored in the Bacterial Culture Collection of the Department of Agriculture, Forestry, Nature and Energy of the University of Tuscia at $-80^{\circ} \mathrm{C}$ in nutrient glycerol agar. Strains were routinely grown on nutrient agar (NA) for 48 to $72 \mathrm{~h}$ at $27^{\circ} \mathrm{C}$.

DNA extraction. Genomic DNA was extracted from single colonies grown for $48 \mathrm{~h}$ at $27^{\circ} \mathrm{C}$ on NA medium. Approximately 2 $\times 10^{9}$ cells were used for DNA extraction with the PureLink Genomic DNA kit (Invitrogen) according to the manufacturer's in-

Table 1. Bacterial strains used in this study, their source, geographic origin, and host of isolation

\begin{tabular}{|c|c|c|c|c|}
\hline Pseudomonas sp. and pathovar & Strain code & Source ${ }^{a}$ & Isolation country, (site), year & Host species (cultivar) \\
\hline \multirow[t]{32}{*}{ Pseudomonas syringae pv. actinidiae } & KW1 & Y. Takikawa & Japan (Shizuoka) 1984 & Actinidia deliciosa (Hayward) \\
\hline & $\mathrm{KW} 11^{\mathrm{b}}$ & Y. Takikawa & Japan (Shizuoka) 1984 & A. deliciosa (Hayward) \\
\hline & 4911 & CFBP & Japan (Shizuoka) 1984 & A. deliciosa (Hayward) \\
\hline & 4912 & CFBP & Japan (Shizuoka) 1984 & A. deliciosa (Hayward) \\
\hline & 5095 & CFBP & Japan (-) 1988 & A. chinensis (-) \\
\hline & 5097 & CFBP & Japan (-) 1988 & A. chinensis (-) \\
\hline & $\mathrm{Kn} 2$ & Y.J. Koh & Korea (-) 1997 & A. chinensis(-) \\
\hline & 23663 & KCTC & Korea (Jeonnam) 1989 & A. chinensis (-) \\
\hline & 23664 & KCTC & Korea (Jeonnam) 1989 & A. chinensis (-) \\
\hline & PSA92 & Scortichini & Italy (Latium) 1992 & A. deliciosa (Hayward) \\
\hline & 7285 & CFBP & Italy (Veneto) 2008 & A. chinensis (Jin Tao) \\
\hline & $7286^{\mathrm{b}}$ & CFBP & Italy (Latium) 2008 & A. chinensis (Hort16A) \\
\hline & 7287 & CFBP & Italy (Latium) 2008 & A. deliciosa (Hayward) \\
\hline & 490 & DAFNE Unitus & Italy (Calabria) 2010 & A. chinensis (Jin Tao) \\
\hline & 1To & DAFNE Unitus & Italy (Piedmont) 2010 & A. deliciosa (Hayward) \\
\hline & 15ER & A. Calzolari & Italy (Emilia Romagna) 2011 & A. deliciosa (Hayward) \\
\hline & 829 & DAFNE Unitus & Spain (Galicia) 2011 & A. chinensis (Jin Tao) \\
\hline & 830 & DAFNE Unitus & Spain (Galicia) 2011 & A. chinensis (Jin Tao) \\
\hline & 820 & DAFNE Unitus & Portugal (Valença) 2011 & A. deliciosa (Erica) \\
\hline & 832 & DAFNE Unitus & Portugal (S.ta Maria da Feira) 2011 & A. deliciosa (Hayward) \\
\hline & 835 & DAFNE Unitus & Portugal (Vila Boa de Quires) 2011 & A. deliciosa (Hayward) \\
\hline & $1 \mathrm{~F}$ & Anses & France (Aquitaine) 2010 & A. chinensis (Jin Tao) \\
\hline & $5 \mathrm{~F}$ & Anses & France (Rhone Alpes) 2010 & A. deliciosa (Hayward) \\
\hline & $14 \mathrm{~F}$ & Anses & France (Aquitaine) 2010 & A. chinensis (Hort16A) \\
\hline & LSV38.17 & & Switzerland (-) 2011 & $\ldots$ \\
\hline & $\mathrm{CH} 2010-5^{\mathrm{b}}$ & L. Hwang & China (Shaanxi) 2010 & A. chinensis (Hongyang) \\
\hline & CH2010-6 & L. Hwang & China (Shaanxi) 2010 & A. chinensis (Hongyang) \\
\hline & CH2010-7 & L. Hwang & China (Shaanxi) 2010 & A. chinensis (Hongyang) \\
\hline & 18839 & ICMP & New Zealand (Bay of Plenty) 2011 & A. deliciosa (Hayward) \\
\hline & 18875 & ICMP & New Zealand (Bay of Plenty) 2011 & A. deliciosa (Hayward) \\
\hline & 18804 & ICMP & New Zealand (Bay of Plenty) 2010 & A. chinensis (-) \\
\hline & 18882 & ICMP & New Zealand (Nelson) 2010 & A. chinensis (Gold) \\
\hline \multirow[t]{2}{*}{ P. syringae pv. theae } & 2598 & NCPPB & Japan (-) 1970 & $\begin{array}{l}\text { Thea sinensis } \\
\text { S }\end{array}$ \\
\hline & 2599 & NCPPB & Japan (-) 1970 & T. sinensis \\
\hline \multirow[t]{3}{*}{ P. syringae pv. avellanae ${ }^{\mathrm{c}}$} & 4224 & NCPPB & Italy (-) 1994 & Corylus avellana \\
\hline & 4226 & NCPPB & Greece (-) 1987 & Corylus avellana \\
\hline & Pav 34 & DAFNE Unitus & Italy (-) & C. avellana \\
\hline P. syringae pv. morsprunorum & 1871 & NCPPB & Italy (-) 1965 & Prunus avium \\
\hline$P$. syringae pv. tomato & 1323 & CFBP & France (Loire) 1971 & Lycopersicon esculentum \\
\hline P. syringae pv. maculicola & 2038 & NCPPB & Unite Kingdom (-) 1967 & Brassica oleracea \\
\hline$P$. syringae pv. papulans & 1754 & CFBP & Canada (-) 1973 & Malus sylvestris \\
\hline$P$. syringae pv. aptata & 5428 & CFBP & Morocco (-) 1996 & Cucumis melo \\
\hline P. syringae pv. lachrymans & 6463 & CFBP & Hungary (-) 1958 & C. sativus \\
\hline$P$. syringae pv. pisi & 2105 & CFBP & New Zealand (-) 1969 & Pisum sativum \\
\hline \multirow{2}{*}{$P$. syringae pv. syringae } & $3909 \mathrm{~B}, 1$ & A. Calzolari & Italy (Emilia Romagna) 2009 & A. chinensis \\
\hline & 4250,1 & A. Calzolari & Italy (Emilia Romagna) 2009 & A. chinensis \\
\hline P. viridiflava & $4254 \mathrm{~A}, 1$ & A. Calzolari & Italy (Emilia Romagna) 2009 & A. chinensis \\
\hline
\end{tabular}

${ }^{a}$ Acronyms for microbial collection: CFBP = Collection Française de Bactéries associées aux Plantes; KCTC = Korean Collection for Type Culture; ICMP = International Collection of Microorganisms from Plants; NCPPB = National Collection of Plant Pathogenic Bacteria.

${ }^{\mathrm{b}}$ Strains representative of the three main populations selected to be used in sensitivity tests.

${ }^{\mathrm{c}}$ Now only Pseudomonas avellanae. 
structions for gram-negative bacteria. The concentration of the eluted DNA was estimated by a fluorimetric device (Qubit; Invitrogen, Life Technologies Italia), adjusted to a final concentration of $50 \mathrm{ng} / \mu \mathrm{l}$ with Tris-EDTA buffer $(10 \mathrm{mM}$ Tris- $\mathrm{HCl}$ and $1 \mathrm{mM}$ EDTA, pH 8.0) and kept at $-20^{\circ} \mathrm{C}$ until use.

Primer design and multiplex-PCR amplification. All primer pairs were designed from sequenced $P$. syringae pv. actinidiae genomes available from the National Center for Biotechnology (NCBI) and with primer 3 software (http://frodo.wi.mit.edu. Primers were synthesized by Primm srl. The position of the amplicons in the genome and the relative primer sets used for the detection of $P$. syringae pv. actinidiae populations in multiplex-PCR (m-PCR) are specified in Table 2. Reactions were first carried out independently for each primer pair. Each reaction consisted of a 50- $\mu$ l total volume mixture containing $25 \mu \mathrm{l}$ of GoTaq Colorless Master Mix 2X (Promega Corporation), $1 \mu$ l of template DNA, $0.8 \mu \mathrm{M}$ each primer, and sterile distilled water (SDW) to the final volume. All four primers were used in each reaction mixture, with primer concentration adjusted to obtain amplifications with comparable intensity. The $50 \mu \mathrm{l}$ of $\mathrm{m}$-PCR mixture consisted of $25 \mu \mathrm{l}$ of GoTaq Colorless Master Mix 2X (Promega Corporation), $1 \mu \mathrm{l}$ of template DNA, $0.30 \mu \mathrm{M}$ primer pair $P$. syringae pv. actinidiae, $0.80 \mu \mathrm{M}$ primer pair Europe, $0.60 \mu \mathrm{M}$ primer pairs $\mathrm{J} / \mathrm{K}$ and China (Table 2), and SDW to the final volume. Amplifications were carried out in a C1000 gradient thermal cycler (Bio-Rad Laboratories srl) and optimized to the following conditions: an initial denaturation step at $95^{\circ} \mathrm{C}$ for $10 \mathrm{~min}$; followed by 40 serial cycles of a denaturation step of $95^{\circ} \mathrm{C}$ for $30 \mathrm{~s}$, annealing at $60^{\circ} \mathrm{C}$ for $30 \mathrm{~s}$, and extension at $72^{\circ} \mathrm{C}$ for $75 \mathrm{~s}$; and a final extension step at $72^{\circ} \mathrm{C}$ for $5 \mathrm{~min}$. A negative control (no template DNA) was included in each batch of m-PCRs. The amplification products were detected by electrophoresis of $5 \mu \mathrm{l}$ of each amplification mixture in a $2 \%$ agarose gel in $1 \times$ Tris-acetate-EDTA buffer. Gels were stained with GelRed (Biotium Inc.). At least three replicate PCR amplifications were carried out on different days for each strain.

Specificity, sensitivity, and reproducibility. The sensitivity of the assay was tested using both pure DNA and bacterial suspensions of one representative strain for each of the investigated populations (Table 1, strains labeled with ${ }^{\mathrm{b}}$ ). Purified genomic DNA (50 ng) of each representative strain was serially diluted in 10-fold increments in SDW down to $5 \mathrm{fg}$ of DNA per PCR. Also, bacterial suspensions of each representative strain were prepared from logphase cultures on nutrient broth and adjusted to a concentration of $5 \times 10^{8} \mathrm{CFU} \mathrm{ml}{ }^{-1}$; then, each suspension was 10 -fold diluted seven times to $5 \times 10^{1} \mathrm{CFU} \mathrm{ml^{-1 }}$ in SDW. These dilutions were used to determine both the initial concentration of each bacterium by surface plating of $100 \mu \mathrm{l}$ onto NA plates, as well as for subsequent crude DNA extraction for PCR. DNA was extracted by heating 100 $\mu \mathrm{l}$ of each dilution at $95^{\circ} \mathrm{C}$ for $10 \mathrm{~min}$; then, the suspensions were centrifuged for 2 min at $12,500 \times g$ and $1 \mu$ of the supernatant was added directly to the PCR mixture. All m-PCRs performed to assess both specificity and limits of detection of the assay were done in triplicate.

Assay evaluation on kiwifruit samples artificially inoculated with $P$. syringae pv. actinidiae. For direct detection of $P$. syringae pv. actinidiae in kiwifruit tissues, artificially inoculated plants were used. One-year-old plantlets of A. deliciosa 'Hayward' and $A$. chinensis 'Hort16A' were maintained in a growth chamber with photoperiod of $16 \mathrm{~h}$ of day and $8 \mathrm{~h}$ of night at $25^{\circ} \mathrm{C}$; for artificial inoculation, plants were enclosed in clear sterile plastic bags overnight to promote stomatal opening, then were sprayed with $5 \mathrm{ml}$ of a P. syringae pv. actinidiae (strain 7286$)$ bacterial suspension $\left(10^{8}\right.$ $\mathrm{CFU} \mathrm{ml} \mathrm{m}^{-1}$ ) in SDW. Control plants were inoculated with the same amount of SDW. Symptoms appeared after 10 to 15 days; then, approximately $100 \mathrm{mg}$ of leaf tissue surrounding necrotic spots was aseptically removed, crushed in a sterile mortar, and used directly for DNA extraction with the DNeasy Plant Mini Kit (Qiagen) according to the manufacturer's instructions. The same procedure was carried out for control plants. Aliquots of extracted DNA $(1 \mu \mathrm{l}$ each) were directly used for m-PCR amplification as described above.

Assay evaluation on kiwifruit samples naturally infected with $\boldsymbol{P}$. syringae pv. actinidiae. Leaves of kiwifruit plants with symptoms referable to $P$. syringae pv. actinidiae were collected in two orchards of both A. deliciosa Hayward (6-year-old plants) and A. chinensis 'JinTao' (3-year-old plants) (30 samples per orchard in total). The protocol described for artificially inoculated plants was also used for DNA extraction and for m-PCR amplification. Moreover, for each sample, a portion of symptomatic tissue was used for classical bacterial isolation. About $100 \mathrm{mg}$ of leaf tissue were homogenized and plated on NA. Plates were incubated at $27^{\circ} \mathrm{C}$ for 24 to $48 \mathrm{~h}$ and observed under the microscope. In all cases, a single morphotype was recovered. Single colonies were then restreaked on the same medium and incubated for another 24 h. Approximately $2 \times 10^{9}$ cells were used for DNA extraction using the PureLink Genomic DNA kit (Invitrogen) according to the manufacturer's instructions for gram-negative bacteria and analyzed by m-PCR as described above.

\section{Results}

Primer design. A first primer pair was designed to specifically detect $P$. syringae pv. actinidiae but not any related $P$. syringae pathovar. For this, a primer pair was designed to amplify a portion of the hopZ3 gene sequence that is conserved among the nine completely sequenced $P$. syringae pv. actinidiae strains but different from the hopZ3 sequences of pv. theae and all other pathovars retrievable from the NCBI database with the BLAST algorithm. The predicted amplicon, referred to as the "P. syringae pv. actinidiae" amplicon, is $311 \mathrm{bp}$ long and the primers sequences are $P$. syringae pv. actinidiae F (CAGAGGCGCTAACGAGGAAA) and $P$. syringae pv. actinidiae R (CGAGCATACATCAACAGGTCA). The corresponding sequence is located in the published genome sequence of $P$. syringae pv. actinidiae strain CFBP7286 between base pairs 7,677 and 7,987 of scaffold 12383_336, contig 1 (accession number: AGNO01000134).

A region within the PPHGI-1-like genomic island (24) was chosen to design three additional primer pairs to distinguish European, Chinese, and Japanese/Korean P. syringae pv. actinidiae strains from each other. The first primer pair, which was first described by Mazzaglia et al. (24), was designed to amplify a region present only in the sequenced genomes of $P$. syringae pv. actinidiae strains isolated during the current bacterial canker of kiwifruit outbreak in

Table 2. Primers used in this study: amplicon name, primer sequence, name of the Pseudomonas syringae pv. actinidiae strain based on which the primer pair was designed, position of the amplicon in the strain's genome, and accession number of the genome used for primer design

\begin{tabular}{|c|c|c|c|c|}
\hline Amplicon & Primer sequence $\left(5^{\prime}-3^{\prime}\right)$ & Strain & Amplicon position in genome & $\begin{array}{c}\text { Accession } \\
\text { number }\end{array}$ \\
\hline P. syringae pv. actinidiae & $\begin{array}{l}\text { CAGAGGCGCTAACGAGGAAA } \\
\text { CGAGCATACATCAACAGGTCA }\end{array}$ & CFBP7286 & 7,677-7,987, scaffold 12383_336, contig_1 & AGNO01000134 \\
\hline Europe & $\begin{array}{l}\text { TGGTGATCGTCTGGATGTGT } \\
\text { ATTATGCTCCTGGCTCATGG }\end{array}$ & CFBP7286 & 54,930-55,662, scaffold 12383_2218, contig_5 & AGNO01000423 \\
\hline China & $\begin{array}{l}\text { GGAGTTCCAGCAACTGACG } \\
\text { CGCTCAAGATCCTTTTCCAT }\end{array}$ & CH2010-6 & 28,169-28,777, scaffold 12384_102, contig_1 & AGUH01000096 \\
\hline Japan/Korea & $\begin{array}{l}\text { AGCAACGGTGGTTTGTTTTC } \\
\text { AAATGTTTGCCAGCCAAGTC }\end{array}$ & M302091 & $8,118-8,371$, contig_26.3 & AEAL01000253 \\
\hline
\end{tabular}


Europe. The PCR product size of this "European" amplicon is 733 $\mathrm{bp}$ and the primer sequences are Europe $\mathrm{F}$ (TGGTGATCGTCT GGATGTGT) and Europe R (ATTATGCTCCTGGCTCATGG). This region is located in the published genome sequence of $P$. syringae pv. actinidiae strain CFBP7286 between base pairs 54,930 and 55,662 of scaffold 12383_2218 contig 5 (accession number: AGNO01000423). The second population-specific primer pair was designed to amplify a 254-bp region present only in the sequenced genomes of $P$. syringae pv. actinidiae strains isolated in Japan and Korea; the primers are $\mathrm{J} / \mathrm{K}$ F (AGCAACGGT GGTTTGTTTTC) and J/K R (AAATGTTTGCCAGCCAAGTC). The amplified region is located in the published genome sequence of $P$. syringae pv. actinidiae strain M302091 between base pairs 8,118 and 8,371 on contig 26.3 (accession number: AEAL01000253). The last primer pair was designed to amplify a 609-by fragment of the PPHGI-1 island present only in the sequenced genomes of $P$. syringae pv. actinidiae strains isolated in China; the primer sequences are China F (GGAGTTCCAGCA ACTGACG) and China R (CGCTCAAGATCCTTTTCCAT). The PCR product is located in the published genome sequence of $P$. syringae pv. actinidiae strain CH2010-6 between base pairs 28,169 and 28,777 on scaffold 12384_102 contig_1 (accession number: AGUH01000096).

Specificity. The identification of a $P$. syringae pv. actinidiae strain as a member of the European population requires the amplification of both the "P. syringae pv. actinidiae" and the "European" amplicon; identification as a member of the Japanese/Korean group requires the amplification of both the " $P$. syringae pv. actinidiae" and the " $\mathrm{J} / \mathrm{K}$ " amplicon; and identification as a member of the Chinese population requires the amplification of both the "P. syringae pv. actinidiae" and the "Chinese" amplicons. Results employing all four primers in a single m-PCR assay with 32 P. syringae pv. actinidiae strains and 15 isolates of different $P$. syringae pathovars and Pseudomonas spp. are shown in Figure 1 . The expected $P$. syringae pv. actinidiae fragment of $311 \mathrm{bp}$ and the expected $\mathrm{J} / \mathrm{K}$ fragment of $254 \mathrm{bp}$ were amplified from the six Japanese and three Korean strains (lanes 2 to 10). Of the 16 European strains assayed (lanes 12 to 25), 15 produced a PCR amplification of the expected $P$. syringae pv. actinidiae fragment (311 bp) and the expected European amplicon (733 bp). The single exception was strain PSA92, which gave the amplification profile typical of Japanese/Korean strains (lane 11). The expected $P$. syringae pv. actinidiae fragment of $311 \mathrm{bp}$ and Chinese amplicon of 609 bp were amplified from the three Chinese strains assayed (lanes 26 to 28). Four strains were assayed from New Zealand, only two of which cause cankers on kiwi (9). Amplicons indicative of the Chinese strain group were amplified from the two cankercausing strains (Fig. 1, lanes 29 and 30). DNA was not amplified from the other two strains, suggesting that these two strains are not in pv. actinidiae (Fig. 1, lanes 31 and 32). Finally, all strains belonging to different $P$. syringae pathovars or Pseudomonas spp. did not produce any amplicons (lanes 33 to 47).

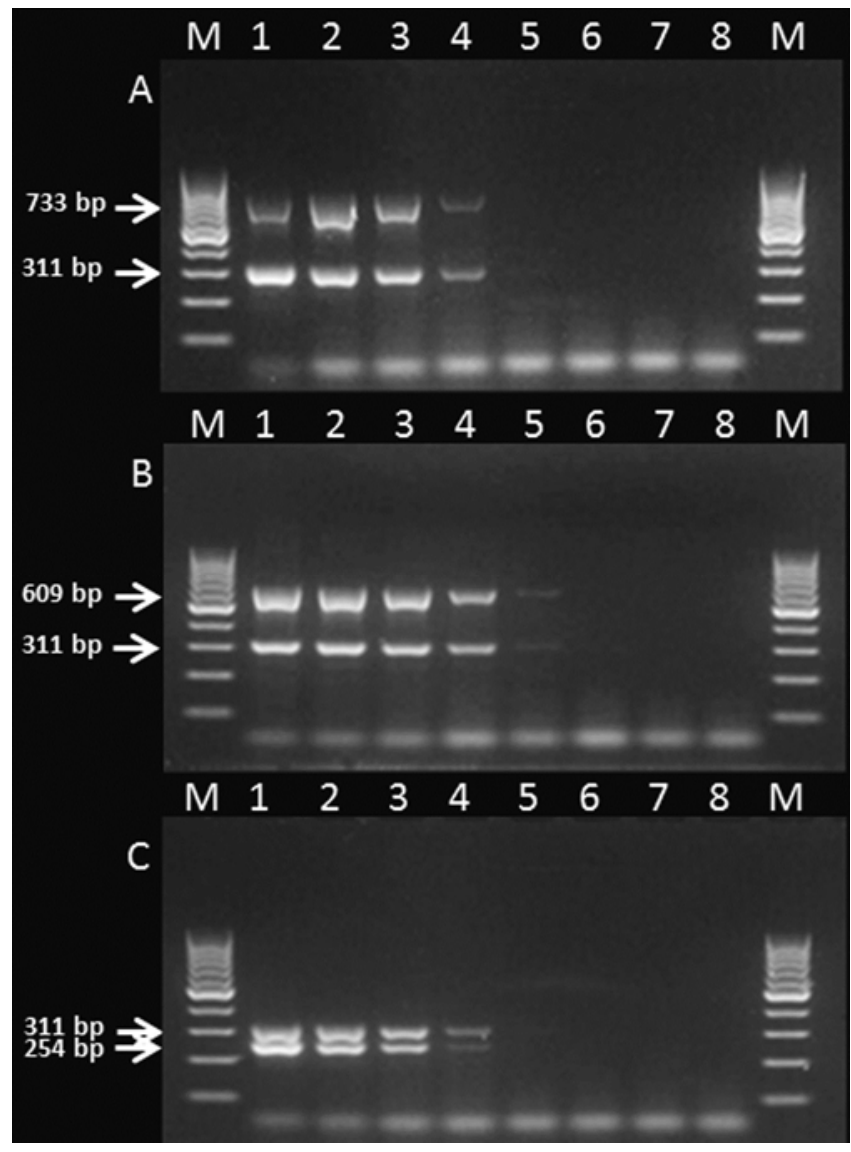

Fig. 2. Sensitivity of detection of purified DNA with all four primer pairs. Polymerase chain reaction amplification from a 10 -fold dilution series of purified DNA from Pseudomonas syringae pv. actinidiae strains A, KW11; B, 7286; and C, CH2010-5. Lane 1, $50 \mathrm{ng}$; lane 2, $5 \mathrm{ng}$; lane 3, $0.5 \mathrm{ng}$; lane 4, $50 \mathrm{pg}$; lane 5, $5 \mathrm{pg}$; lane 6, 0.5 pg; lane 7, $50 \mathrm{fg}$; lane 8, control, no template DNA. M, molecular marker (GeneRuler 100-bp DNA ladder; Genenco).

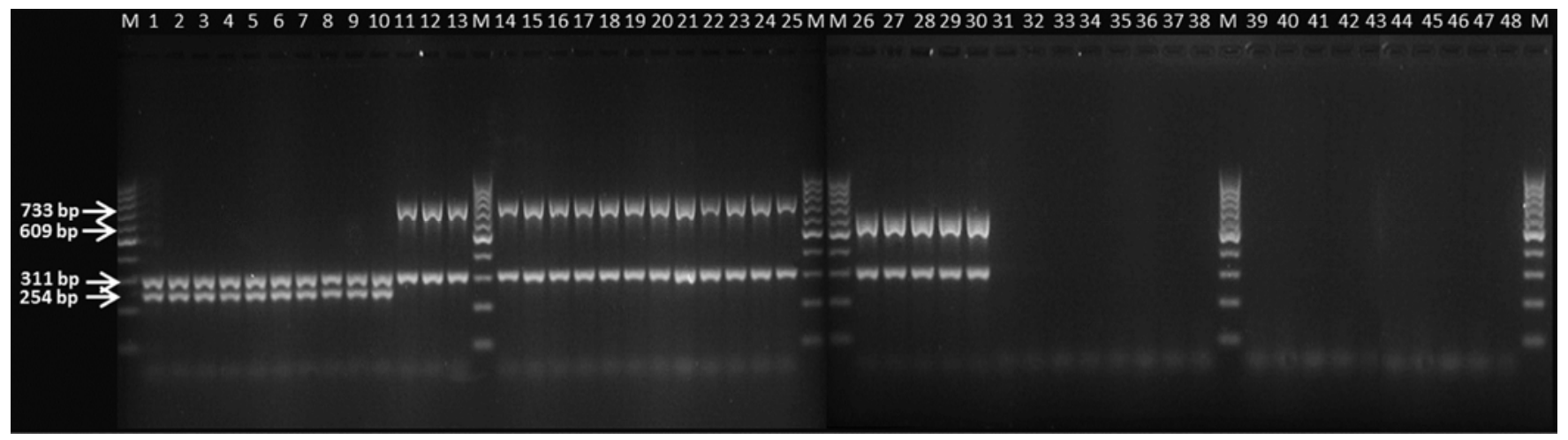

Fig. 1. Multiplex polymerase chain reaction amplification with all four primer pairs. Lanes 1-6: Japanese Pseudomonas syringae pv. actinidiae strains (KW1, KW11, 4911, 4912, 5095, and 5097); lanes 7-9: Korean P. syringae pv. actinidiae strains (Kn2, 23663, and 23664); lanes 10-25: European P. syringae pv. actinidiae strains (PSA92, 7285, 7286, 7287, 490, 1To, 15ER, 829, 830, 820, 832, 835, 1F, 5F, 14F, and LSV38.17); lanes 26-28 Chinese P. syringae pv. actinidiae strains (CH2010-5, CH2010-6, and CH2010-7); lanes 29-30: New Zealand P. syringae pv. actinidiae strains (18839 and 18875); lanes 31-32: New Zealand strains isolated from kiwifruit plants but that do not cause canker (18804 and 18882); lanes 33-34: P. syringae pv. theae (2598 and 2599); lane 35: P. syringae pv. tomato; lane 36: P. syringae pv. papulans; lane 37: P. syringae pv. aptata; lane 38: P. syringae pv. lachrymans; lane 39: P. syringae pv. pisi; lanes 40-41: P. syringae pv. syringae (3909 b,1 and 4250,1); lanes 42-44: P. avellanae (NCPPB 4224, NCPPB4226, and Pav34); lane 45: P. syringae pv. morsprunorum; lane 46: P. syringae pv. maculicola; lane 47: P. viridiflava; lane 48: control, no template DNA. M: molecular marker (GeneRuler 100-bp DNA ladder; Genenco). Arrows indicate the P. syringae pv. actinidiae amplicon (311 bp), European amplicon (733 bp), Japanese/Korean amplicon (609 bp), and Chinese amplicon (254 bp), respectively. 
Sensitivity. The sensitivity of the m-PCR assay was in the range from 5 to $50 \mathrm{pg}$ for all tested strains when $1-\mu \mathrm{l}$ aliquots of serial 10 -fold dilutions of purified DNA of the selected representative strains were used (Fig. 2). The detection limit for m-PCR assay was also investigated using 10-fold serially diluted bacterial suspensions. Amplification of the expected fragments was clearly visible on the gels down to a concentration corresponding to $5 \times$ $10^{2} \mathrm{CFU} / \mathrm{PCR}$ for all tested strains (Fig. 3). However, the fragment of $311 \mathrm{bp}$ was often visible even using only $5 \times 10^{1} \mathrm{CFU} / \mathrm{PCR}$.

$P$. syringae pv. actinidiae detection in artificially inoculated and naturally infected kiwifruit samples. The pathogen was successfully detected in all the symptomatic samples obtained from artificially inoculated plantlets of both A. deliciosa and A. chinensis after amplification from $1 \mu \mathrm{l}$ of extracted DNA. No amplification products were obtained from water-inoculated plants (Fig. 4).

The pathogen was also detected without any failure in all 60 symptomatic samples obtained from naturally infected plants of both $A$. deliciosa and A. chinensis after amplification from $1 \mu \mathrm{l}$ of extracted DNA (Fig. 5). All samples produced the two amplicons referable to the European type. The molecular analysis of bacteria isolated from the same samples fully confirmed these results.

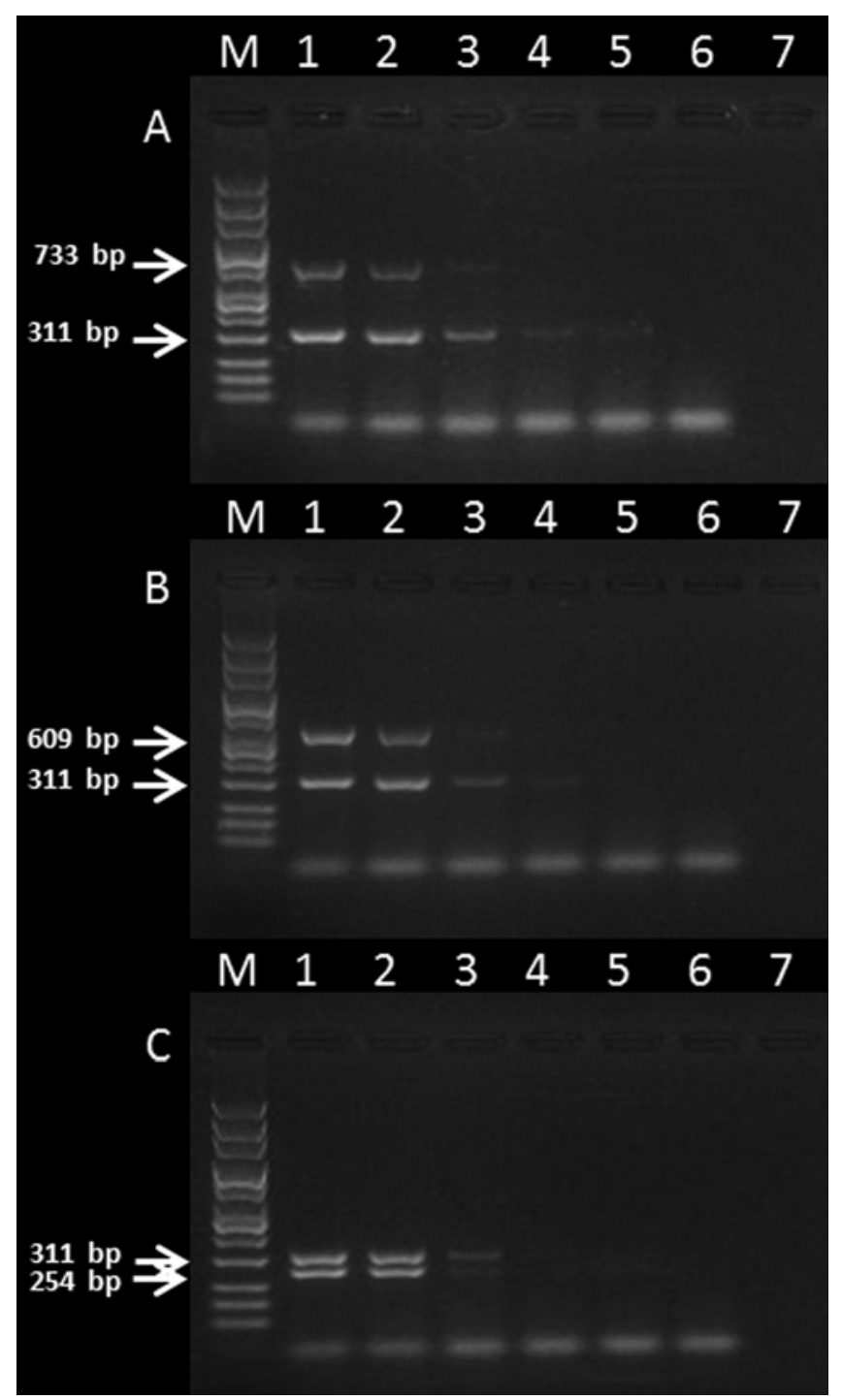

Fig. 3. Sensitivity of detection of bacterial suspensions with all four primer pairs. Polymerase chain reaction (PCR) amplification from a 10 -fold dilution series of bacterial suspension of Pseudomonas syringae pv. actinidiae strains A, KW11; B, 7286; and C, CH2010-5. Lane 1,5 × $10^{4}$ CFU/PCR (undiluted sample); lane 2, $5 \times$ $10^{3} \mathrm{CFU} / \mathrm{PCR}$; lane 3, $5 \times 10^{2} \mathrm{CFU} / \mathrm{PCR}$; lane 4, $5 \times 10^{1} \mathrm{CFU} / \mathrm{PCR}$; lane 5, $5 \times 10^{0}$ CFU/PCR; lane 6, $5 \times 10^{-1} \mathrm{CFU} / \mathrm{PCR}$; lane 7, control, no template DNA. M, molecular marker (SharpMass 100 plus; EuroClone).

\section{Discussion}

P. syringae pv. actinidiae is difficult to identify by morphological observation, biochemical tests, or pathogenicity assays due to many features shared with other $P$. syringae pathovars and other pseudomonads. However, an accurate identification of $P$. syringae pv. actinidiae is important because it is essential to obtain a reliable picture of the phytosanitary situation in an orchard before intervening with any control measures. In fact, the earliest foliar symptoms during the vegetative season can be easily confused with those induced by other more innocuous bacterial pathogens of kiwifruit such as $P$. syringae pv. syringae and $P$. viridiflava, which do not require the same drastic interventions required for $P$. syringae pv. actinidiae, including the eradication of diseased plants (27). Moreover, an assay able to distinguish P. syringae pv. actinidiae from closely related bacteria is essential when screening stocks of vegetative material for propagation, planting of new orchards, and phytosanitary controls before importation.

To address this challenge, we described here a novel and rapid method for detection of $P$. syringae pv. actinidiae and contemporaneous identification of three $P$. syringae pv. actinidiae populations with different geographic origins.

This molecular test is discriminatory: all non- $P$. syringae pv. actinidiae $P$. syringae pathovars and $P$. viridiflava assayed gave a clear negative result while all $P$. syringae pv. actinidiae strains

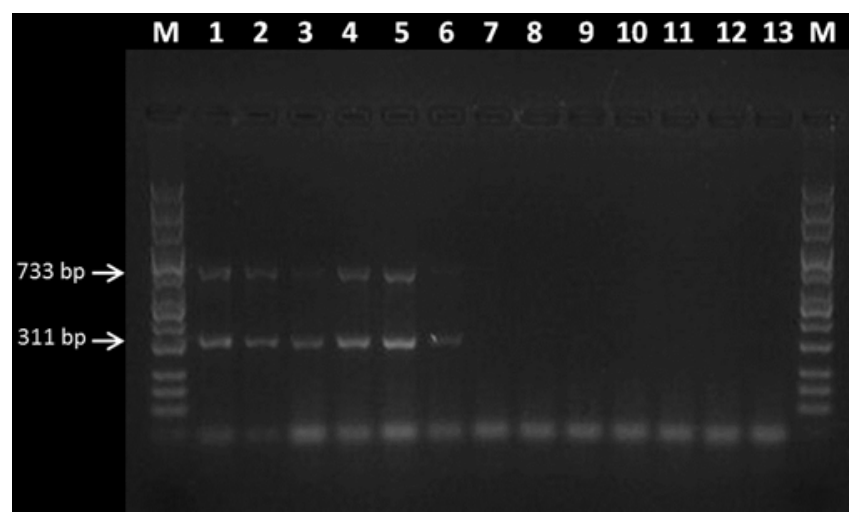

Fig. 4. Multiplex polymerase chain reaction amplification of DNA from symptomatic portions of leaves artificially inoculated with a suspension of Pseudomonas syringae pv. actinidiae strain 7286 (lanes 1-6) or with sterile distilled water (lanes 7-12); lane 13; negative control, no template DNA; M: molecular marker (SharpMass 100 plus; EuroClone).

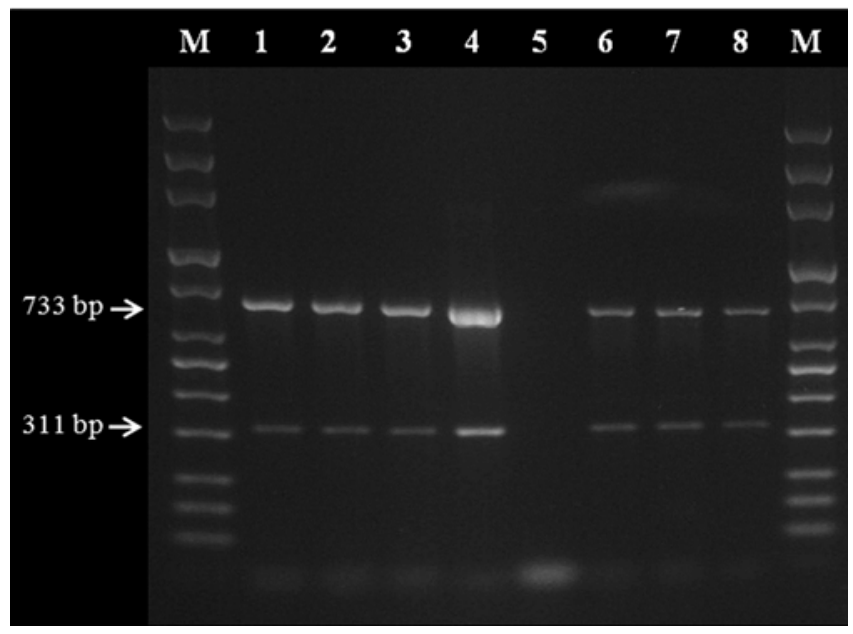

Fig. 5. Multiplex polymerase chain reaction amplification of DNA from symptomatic portions of naturally infected tissues of Actinidia deliciosa 'Hayward' (lanes 1-3) and A. chinensis 'JinTao' (lane 6-8); lane 4: purified DNA of Pseudomonas syringae pv. actinidiae strain 7286 as positive control; lane 5; negative control, no template DNA; M: molecular marker (SharpMass 100 plus; EuroClone). 
gave the expected amplification pattern, giving additional information about their geographic origin.

At first, strain PSA92 may appear to be an exception because this strain was isolated in Italy in 1992 but gave the Japanese/Korean amplicon profile. However, this strain was isolated during a very limited outbreak in regard to both time and geography. Using a variety of different molecular methods, including whole-genome sequencing, this strain was previously found to be very similar to Japanese $P$. syringae pv. actinidiae strains $(9,14,23,24,31,38)$ and, thus, was probably imported from Japan. After 1992, P. syringae pv. actinidiae was not reported anymore in Europe until the severe $P$. syringae pv. actinidiae outbreak in 2008.

The first primer pair was designed based on hopZ3, a gene which encodes a type III secreted effector involved in the pathogenesis of $P$. syringae (38). This gene is present and $100 \%$ identical in DNA sequence in all sequenced $P$. syringae pv. actinidiae genomes $(6,22,24)$. P. syringae pv. actinidiae hopZ3 allele sequence comparisons of all available hopZ3 alleles allowed the design of a primer pair specific to $P$. syringae pv. actinidiae. That this primer pair amplifies a fragment of the expected size from all $P$. syringae pv. actinidiae strains isolated from multiple locations around the world from 1984 to today confirms that this gene is conserved in all currently known $P$. syringae pv. actinidiae populations. On the other hand, no amplification was detected with the two $P$. syringae pv. actinidiae isolates ( $P$. syringae pv. actinidiaeLV) from New Zealand that only cause mild foliar symptoms similar to P. syringae pv. syringae but do not cause any cankers (9). Other Pseudomonas taxa also tested negative, confirming the specificity of the developed assay. This suggests that the hopZ3 primers could be used alone in a PCR assay to detect $P$. syringae pv. actinidiae or distinguish $P$. syringae pv. actinidiae strains from other pseudomonads.

The other primers were designed from a genomic island that has a gene content and gene order similar to the PPHGI-1 island of $P$. syringae pv. phaseolicola (25) and which varies among European, Chinese, and New Zealand $P$. syringae pv. actinidiae strains (24). Although these populations are closely related, enough variation is present in the PPHGI-1-like islands among the sequenced strains to develop a PCR assay capable of distinguishing among them.

The results confirm and extend our previous finding that the $P$. syringae pv. actinidiae population in Europe is highly homogeneous and distinct from the ones in New Zealand and China (24). Furthermore, several independent $\mathrm{m}$-PCR experiments on additional European isolates obtained since 2008 to date have constantly produced the correct European amplicons (data not shown). Not enough isolates are currently available to us to determine whether the $P$. syringae pv. actinidiae populations in China and in New Zealand are also homogeneous.

The described assay does not distinguish between the different genotypes known to exist in the Japanese and Korean $P$. syringae pv. actinidiae population. If necessary, one could use additional primers targeted to the genes that encode the toxins phaseolotoxin and coronatine, which distinguish the different genotypes in this population from each other $(16,28)$. However, because Japanese and Korean $P$. syringae pv. actinidiae strains currently appear limited to these two countries and are not involved in the current worldwide canker of kiwifruit outbreaks, distinguishing among genotypes within the Japanese/Korean population is currently not a priority.

The limit of detection of $P$. syringae pv. actinidiae using the $\mathrm{m}-$ PCR assay was approximately $5 \times 10^{2} \mathrm{CFU} \mathrm{m} l^{-1}$ or 5 to $50 \mathrm{pg}$ of purified DNA. This detection limit was independent of the genotype that was used as template. This could become very important in the hypothetical case of simultaneous infection by strains belonging to different populations.

The assay developed here has already proven to be reliable in detecting the pathogen and assigning it to a specific population directly from symptomatic kiwifruit tissues, making the test useful for testing field samples suspected of $P$. syringae pv. actinidiae infection directly without the need of going through time-consum- ing isolation steps. Having a routine analysis protocol for plant samples will permit technicians to precisely evaluate each single plant with suspect symptoms and prompt the farmers to enact immediately any measures to limit the spread of the pathogen or eradicate it. Possibly, the sensitivity of the method is even at a level sufficient to detect latent infections of the pathogen in vegetative tissue or at low levels in pollen, one of the suggested vehicles of spread of $P$. syringae pv. actinidiae $(33,35)$, but this remains to be determined.

In conclusion, the newly developed m-PCR assay described here provides a means for rapid and highly discriminatory populationlevel identification of $P$. syringae pv. actinidiae from either isolated bacterial DNA, cultured bacteria, or DNA extracted from symptomatic kiwifruit leaves. The assay can be expected to benefit plant health and quarantine operations, facilitate epidemiological studies, and help development and application of intervention strategies to slow the spread of this recently emerged plant disease.

\section{Acknowledgments}

The research in the Balestra laboratory is supported by Italian Minister of Agriculture, Food and Forestry Policy (MIPAAF) OIGA number 247; the research in the Vinatzer laboratory is supported by NSF (IOS-0746501). We thank all of our colleagues who supplied bacterial cultures.

\section{Literature Cited}

1. Balestra, G. M., Mazzaglia, A., Quattrucci, A., and Renzi, M. 2009. Current status of bacterial canker spread on kiwifruit in Italy. Australas. Plant Dis. Notes 4:34-36.

2. Balestra, G. M., Mazzaglia, A., Quattrucci, A., and Renzi, M. 2009. Occurrence of Pseudomonas syringae pv. actinidiae in Jin Tao kiwi plants in Italy. Phytopathol. Mediterr. 48:299-301.

3. Balestra, G. M., Mazzaglia, A., Quattrucci, A., Spinelli, R., Graziani, S., and Rossetti, A. 2008. Cancro batterico su Actinidia chinensis. Inf. Agrar. 38:75-76.

4. Balestra, G. M., Renzi, M., and Mazzaglia, A. 2010. First report of bacterial canker of Actinidia deliciosa caused by Pseudomonas syringae pv. actinidiae in Portugal. New Dis. Rep. 22:10. Online publication. http://dx.doi. org/10.5197/j.2044-0588.2010.022.010

5. Balestra, G. M., Renzi, M., and Mazzaglia, A. 2011. First report of Pseudomonas syringae pv. actinidiae on kiwifruit plants in Spain. New Dis. Rep. 24:10. Online publication. http://dx.doi.org/10.5197/j.2044-0588.2011.024 010

6. Baltrus, D. A., Nishimura, M. T., Romanchuk, A., Chang, J. H., Mukhtar, M. S., Cherkis, K., Roach, J., Grant, S. R., Jones, C. D., and Dangl, J. L. 2011. Dynamic evolution of pathogenicity revealed by sequencing and comparative genomics of 19 Pseudomonas syringae isolates. Plos Pathog. 7:e1002132. Online publication. doi:10.1371/journal.ppat.1002132

7. Bastas, K. K., and Karakaya, A. 2012. First report of bacterial canker of kiwifruit caused by Pseudomonas syringae pv. actinidiae in Turkey. Plant Dis. 96:452. Online publication. http://dx.doi.org/10.1094/PDIS-08-110675

8. Biosecurity Australia 2011. Final Pest Risk Analysis Report for Pseudomonas syringae pv. actinidiae Associated with Actinidia (kiwifruit) Propagative Material. Department of Agriculture, Fisheries and Forestry, Canberra, Australia.

9. Chapman, J., Taylor, R., and Alexander, B. 2011. Second Report on Characterization of Pseudomonas syringae pv. actinidiae (Psa) Isolates in New Zealand. Ministry of Agriculture and Forestry Report, May 2011.

10. European Plant Protection Organization 2011. First report of Pseudomonas syringae pv. actinidiae in Chile. EPPO Rep. Serv. No. 3, 2011/055. http://archives.eppo.int/EPPOReporting/2011/Rse-1103.pdf

11. European Plant Protection Organization 2011. First report of Pseudomonas syringae pv. actinidiae in Switzerland. EPPO Rep. Serv. No. 8, 2011/168. http://archives.eppo.int/EPPOReporting/2011/Rse-1108.pdf

12. Everett, K. R., Taylor, R. K., Romberg, M. K., Rees-George, J., Fullerton, R. A., Vanneste, J. L., and Manning, M. A. 2011. First report of Pseudomonas syringae pv. actinidiae causing kiwifruit bacterial canker in New Zealand. Australas. Plant Dis. Notes $6: 67-71$.

13. Fang, Y., Zhu, X., and Wang, Y. 1990. Preliminary studies on kiwifruit diseases in Hunan Province. Sichuan Fruit Sci. Technol. 18:28-29.

14. Ferrante, P., and Scortichini, M. 2010. Molecular and phenotypic features of Pseudomonas syringae pv. actinidiae isolated during recent epidemics of bacterial canker on yellow kiwifruit (Actinidia chinensis) in central Italy. Plant Pathol. 59:954-962.

15. Gallelli, A., L'Aurora, A., and Loreti, S. 2011. Gene sequence analysis for the molecular detection of Pseudomonas syringae pv. actinidiae: Developing diagnostic protocols. J. Plant Pathol. 93:425-435.

16. Han, H. S., Koh, Y. J., Hur, J. S., and Jung, J. S. 2003. Identification and characterization of coronatine-producing Pseudomonas syringae pv. actinidiae. J. Microbiol. Biotechnol. 13:110-118. 
17. Janse, J. D., Rossi, M. P., Angelucci, L., Scortichini, M., Derks, J. H. J., Akkermans, A. D. L., De Vrijer, R., and Psallidas, P. G. 1996. Reclassification of Pseudomonas syringae pv. avellanae as Pseudomonas avellanae (spec. nov.) the bacterium causing canker of hazelnut (Corylus avellana L.). Syst. Appl. Microbiol. 19:589-595.

18. Koh, Y. J., Cha, B. J., Chung, H. J., and Lee, D. H. 1994. Outbreak and spread of bacterial canker in kiwifruit. Korean J. Plant Pathol. 10:68-72.

19. Koh, Y. J., Kim, G. H., Jung, J. S., Lee, Y. S., and Hur, J. S. 2010. Outbreak of bacterial canker on Hort16A (Actinidia chinensis Planchon) caused by Pseudomonas syringae pv. actinidiae in Korea. N.Z. J. Crop Hortic. 38:275282.

20. Koh, Y. J., and Nou, I. S. 2002. DNA Markers for Identification of Pseudomonas syringae pv. actinidiae. Mol. Cells 13:309-314.

21. Lee, J. H., Kim, J. H., Kim, G. H., Jung, J. S., ,Hur J.-S., and Koh, Y. J. 2005. Comparative analysis of Korean and Japanese strains of Pseudomonas syringae pv. actinidiae causing bacterial canker of kiwifruit. Plant Pathol. 21:119-126.

22. Marcelletti, S., Ferrante, P., Petriccione, M., Firrao, G., and Scortichini, M, 2011. Pseudomonas syringae pv. actinidiae draft genomes comparison reveal strain-specific features involved in adaptation and virulence to Actinidia species. PLoS ONE 6:e27297. Online publication. doi:10.1371/ journal.pone.0027297

23. Mazzaglia, A., Renzi, M., and Balestra, G. M. 2011. Comparison and utilization of different PCR-based approaches for molecular typing of Pseudomonas syringae pv. actinidiae strains from Italy. Can. J. Plant Pathol. 33:8-18.

24. Mazzaglia, A., Studholme, D. J., Taratufolo, M. C., Cai, R., Almeida, N. F., Goodman, T., Guttman, D. S., Vinatzer, B. A., and Balestra, G. M. 2012. Pseudomonas syringae pv. actinidiae (PSA) isolates from recent bacterial canker of kiwifruit outbreaks belong to the same genetic lineage. PLoS ONE 7:e36518. Online publication. doi:10.1371/journal.pone.0036518

25. Pitman, A. R., Jackson, R. W., Mansfield, J. W., Kaitell, V., Thwaites, R., and Arnold, D. L. 2005. Exposure to host resistance mechanisms drives evolution of bacterial virulence in plants. Curr. Biol. 15:2230-2235.

26. Rees-George, J., Vanneste, J. L., Cornish, D. A., Pushparajah, I. P. S., Yu, J., Templeton, M. D., and Everett, K. R. 2010. Detection of Pseudomonas syringae pv. actinidiae using polymerase chain reaction (PCR) primers based on the 16S-23S rDNA intertranscribed spacer region and comparison with PCR primers based on other gene regions. Plant Pathol. 59:453-464.

27. Renzi, M., Copini, P., Taddei, A.R., Rossetti, A., Gallipoli, L., Mazzaglia, A., and Balestra, G. M. 2012. Bacterial canker on kiwifruit in Italy:
Anatomical changes in the wood and in the primary infection sites. Phytopathology 102:827-840.

28. Sawada, H., Kanaya, S., Tsuda, M., Suzuki, F., Azegami, K., and Saitou, N 2002. A phylogenomic study of the octase genes in Pseudomonas syringae pathovars: the horizontal transfer of the argk-tox cluster and the evolutionary history of octase genes on their genomes. J. Mol. Evol. 54:437-457.

29. Scortichini, M. 1994. Occurrence of Pseudomonas syringae pv. actinidiae on kiwifruit in Italy. Plant Pathol. 43:1035-1038.

30. Scortichini, M., Marcelletti, S., Ferrante, P., Petriccione, M., and Firrao, G. 2012. Pseudomonas syringae pv. actinidiae: A re-emerging, multi-faceted, pandemic pathogen. Mol. Plant Pathol. Online publication. doi:10.1111/ j.1364-3703.2012.00788.x

31. Scortichini, M., Marchesi, U., and Di Prospero, P. 2002. Genetic relatedness among Pseudomonas avellanae, P. syringae pv. theae and P. s. pv. actinidiae, and their identification. Eur. J. Plant Pathol. 108:269-278.

32. Serizawa, S., Ichikawa, T., Takikawa, Y., Tsuyumu, S., and Goto, M. 1989 Occurrence of bacterial canker of kiwifruit in Japan: Description of symptoms, isolation of the pathogen and screening of bactericides. Ann. Phytopathol. Soc. Jpn. 55:427-436.

33. Stefani, E., and Giovanardi, D. 2011. Dissemination of Pseudomonas syrin gae pv. actinidiae through pollen and its epiphytic life on leaves and fruits. Phytopathol. Mediterr. 50:489-496.

34. Takikawa, Y., Serizawa, S., Ichikawa, T., Tsuyumu, S., and Goto, M. 1989. Pseudomonas syringae pv. actinidiae pv. nov.: The causal bacterium of canker of kiwifruit in Japan. Ann. Phytopathol. Soc. Jpn. 55:437-444

35. Vanneste, J. L., Giovanardi, D., Yu, J., Cornish, D. A., Kay, C., Spinelli, F. and Stefani, E. 2011. Detection of Pseudomonas syringae pv. actinidiae in kiwifruit pollen samples. N.Z. Plant Prot. 64:246-251.

36. Vanneste, J. L., Poliakoff, F., Audusseau, C., Cornish, D. A., Paillard, S., Rivoal, C., and Yu, J. 2011. First report of Pseudomonas syringae pv. actinidiae, the causal agent of bacterial canker of kiwifruit in France. Plant Dis. 95:1311.

37. Vanneste, J. L., Yu, J., and Cornish, D. A. 2010. Molecular characterisations of Pseudomonas syringae pv. actinidiae strains isolated from the recent outbreak of bacterial canker on kiwifruit in Italy. N. Z. Plant Prot. 63:7-14.

38. Vinatzer, B. A., Teitzel, G. M., Lee, M.-W., Jelenska, J., Hotton, S., Fairfax, K., Jenrette, J., and Greenberg, J. T. 2006. The Type III effector repertoire of Pseudomonas syringae B728a and its role in survival and disease on host and non-host plants. Mol. Microbiol. 62:6-44.

39. Young, J. M. 1991. Pathogenicity and identification of the lilac pathogen, Pseudomonas syringae pv. syringae van Hall 1902. Ann. Appl. Biol. 118:283-298 